\title{
Nurses Role in Delivering the Message: The Value of Health Promotion and Patient Education in the Self-Care Management of Adults with Asthma
}

\section{Bridget Murray ${ }^{*}$ and Mary O'Neill}

School of Nursing, Royal College of Surgeons, 123 St. Stephen's Green, Dublin 2, Ireland

"Corresponding author: Murray B, School of Nursing, Royal College of Surgeons, 123 St. Stephen's Green, Dublin 2, Ireland, Tel: +353 (0) 87747 1056; E-mail: bmurray@rcsi.ie

Received date: May 22, 2016; Accepted date: June 23, 2016; Published date: June 30, 2016

Copyright: (c) 2016 Murray B, et al. This is an open-access article distributed under the terms of the Creative Commons Attribution License, which permits unrestricted use, distribution, and reproduction in any medium, provided the original author and source are credited

\begin{abstract}
Background: Asthma affects 235 million people worldwide. In developed countries, 1 in 12 people suffer from asthma. In Ireland this statistic is higher with 1 in 10 individuals suffering from asthma. Nurses are at the forefront in the battle against the effects of asthma on patients. This review aims to examine the critical role of health promotion interventions by nurses in the management of asthma.

Method: This literature review, in conjunction with a presentation slide deck, looks to:

1. Identify asthma triggers as an important source of knowledge for nurses when treating asthma.

2. Explore techniques that improve patient education and self-management of asthma.

3. Highlight the importance of Health promotion in relation to asthma.

Results: From this review it was determined that health promotion in asthma must be an educational initiative where it's amalgamated into nursing practice and becomes on integral part of a nurse's toolkit.

Conclusion: A simple education leaflet detailing what was presented in the enclosed slides was designed following this review to support patient education for the effective self-management of adults with asthma. Further study should be conduct on the long term benefits of this leaflet.
\end{abstract}

Keywords: Asthma; Patient education; Health promotion; Nurse; Asthma

Patient

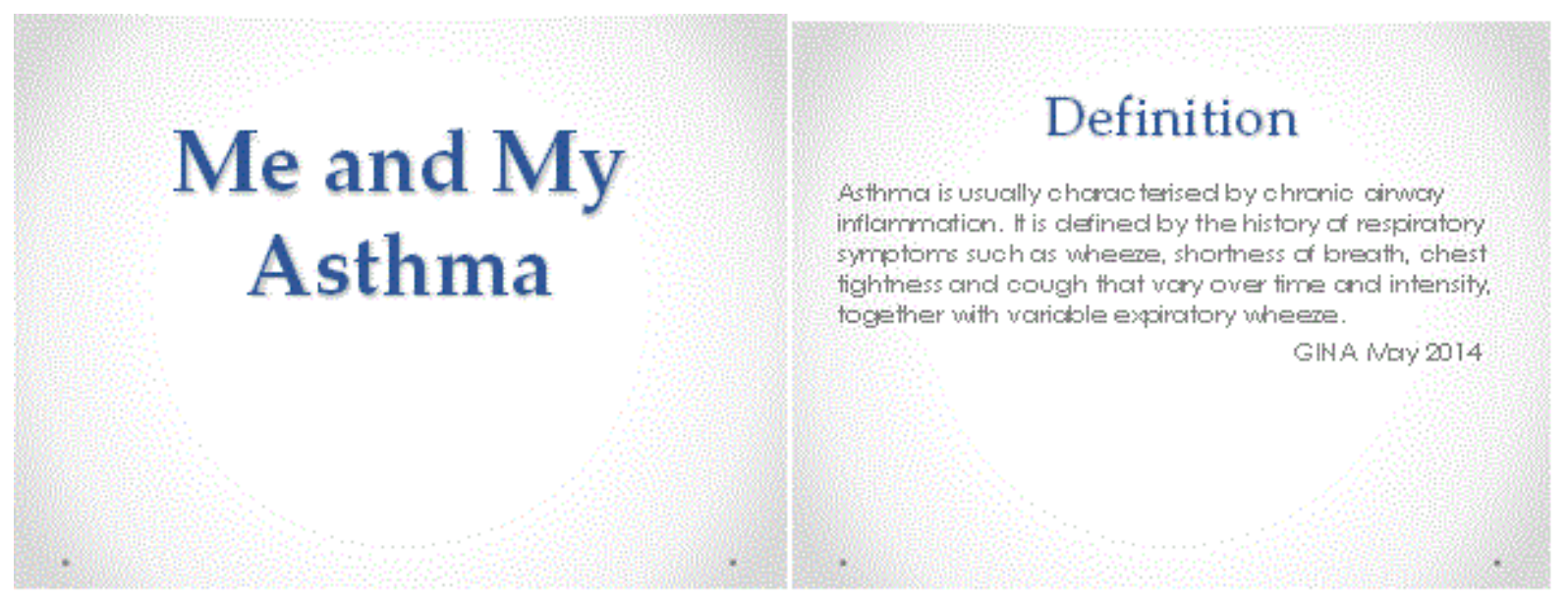

Figure 1: Me and my asthma.

Global Initiative for Asthma (GINA) Guideline [1] defines asthma as a heterogeneous disease, usually characterised by chronic airway inflammation. It is defined within the history of respiratory symptoms such as wheezing, shortness of breath; chest tightness and coughing that vary overtime and in intensity, together with variable expiratory wheezing. As we know Asthma is heterogeneous, many phenotypes have been identified such as allergic intrinsic and non-allergic extrinsic asthma (Figure 1). 
In 2004-2005, the health expenditure due to asthma in Australia was estimated to be 606 million Australian dollars [2] and this is quite a budget to carry on a health system. According to World Health Organisation [3] approximately 235 million people suffer from asthma. The low and lower middle income countries account for $80 \%$ of those asthma deaths. The U.K. National Health Service [4] have reported that about 5.4 million people in the UK are receiving treatment for asthma which is equivalent to 1 in every 12 adults with more prevalence in women rather than man. The U.S. National Institute of Allergy and Infectious Diseases [5] reports similar findings where approximately 25 million suffer from asthma which is equivalent to 1 in every 12 adults and the numbers are increasing with a medical cost to the U.S. of $\$ 56$ billion. According to the Asthma Society of Ireland [6], Ireland had the fourth highest prevalence of asthma in the world. Approximately 470,000 cases in a population of 4,581,296 suffer from asthma, which are nearly one in ten individuals. When measuring Ireland against international findings discussed, it can be shown that Ireland is one of the highest suffers of asthma in the world. What is more alarming is that one individual dies a week from asthma in Ireland. On average, an adult with asthma can miss up to 12 working days a year, this relates to a cost to the society in the region of 501 million Euros a year [6].

In the last decade nurses in Ireland have seen an increase in the amount of health education and health promotion activities integrated into the nursing profession. Nurses are seen as being ideally placed to deliver health promotion due to the close contact they have with both patients and their relatives [7]. All health promotion programmes need to be informed and underpinned by establishing theory and model relevant to the planned interventions [8]. Looking at any of the health promotion sites on the internet, colour and animation to attract the individual is a central theme and this should be an integral part of patient education in nursing practice. The International Council of Nurse [9] Code of Ethics for Nurses states that "nurses have four fundamental responsibilities, to promote and restore health, to prevent illness, and to alleviate suffering of our patients". The Department of Health [10] Your Health is Your Wealth: a Policy Framework for a Healthier Ireland 2012-2020, aims to help people live more fulfilling and healthier lives. A large percentage of asthmatic chronic conditions could be prevented by changing one's lifestyle and avoiding unnecessary risk factors. It is the responsibility of every individual to adopt a healthier lifestyle and to provide a healthier environment and pathway for the next generation. The goal of every nurse is to improve patient' health and when health promotion is used to education patients' it increases control over the health of the patient.

\section{Asthma Triggers}

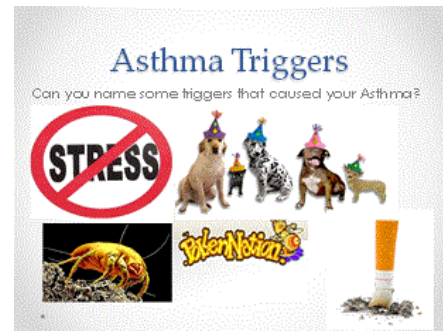

Figure 2: Asthma triggers.
According to Ritz et al. [11] study, asthma triggers linked with adverse asthma attacks and psychological triggers in particular can be associated with a lack of asthma control. For many patients their symptoms of asthma can be triggered by psychological factors like stress. The nurse needs to be aware that patients being exposed to triggers can cause the patient to recall previous memory of the trigger and its affect. Therefore controlling psychological factors reduces the severity of their symptoms and improves the management of the disease. Yorke et al. [12] was unable to draw a conclusion on the benefits of psychological intervention in the treatment of asthma, but it was thought that some psychological intervention help however further evidence based research is required. Extreme emotional expressions like stress and anxiety may cause asthma exacerbation leading to hyperventilation and hypocapnia which can cause a narrowing of the airways resulting in an asthmatic attack [13]. The Mayo Clinic [14] believes that it's unclear if relaxation therapy techniques like yoga and hypnosis can assist asthma suffers but they do seem to reduce their stress levels which is proven to be one of the triggers for asthma. Patients need to be made more aware of their symptoms and the triggers that cause their asthma attacks in order to be better deal with their condition (Figure 2).

An allergen is a substance that causes an allergic reaction in someone who is hypersensitive to it. Dust mites are one of the know allergens to trigger asthma. GINA [1] suggests performing allergy tests to measure specific immunoglobulin in the serum that may identify allergen exposure as a trigger for asthma attacks. Gøtzsche and Johansen in 2011 conducted a research study on how sensitive house dust is on asthma [15]. The study which included 55 randomised trials on 3,121 people did not find an effective control measure to reduce the exposure to dust mites for patients with asthma. Singh and Jaiswal [16] conducted a study on humidity control measures in the home environment of patients with asthma. Their findings showed that there were no significant differences in house dust mite levels and antigen levels in the trial, in contrast to trials conducted in the past. There was also no noteworthy difference in the quality of life, medication requirements, visits to the doctor or emergency department; or hospitalisations for the asthmatic patients in the trial.

It was commonly thought that artificial fibre filled pillows and bedding are less likely to gather allergens than feather-filled pillows and bedding. Campbell and Gibson [17] found evidence that feather bedding may in fact be less likely to cause asthma, although research is still required to make a comparison between feathers and artificial fibres. Abramson et al. [18] review of trials found that immunotherapy, which involves injecting an allergen under the skin, can reduce asthma symptoms, the need for medications and the risk of severe asthma attacks after future exposure to an allergen.

According to Farrell et al. [19] study carried out in Ireland highlighted the link between dampness and respiratory problems in both adults and children that show a clear relationship between damp and mould growth and chronic asthma problems. One of the Vermont Department of Health [20] framework goals was to reduce exposure to environmental triggers in the home and work environment followed by improvement in patient education on asthma and self-management practices. Direct effects on the patients include thermal stress on the body that can increase the risk of respiratory and allergic conditions. Adults that present themselves with obstructive airway conditions such as asthma could be as a direct effect off inhabiting under or possible over insulated heated homes [21]. 
Although pet removal has been recommended in GINA guidelines 2015 on the management of allergic asthma, pet ownership can still be high among asthmatic patients. Kilburn et al. [22] recommends air filtration units in the homes of pet-allergic asthmatics as a solution to reduce allergen exposure. Kilburn et al. [22] notes that complete avoidance of pet allergens is near to impossible, as the allergens can be found in many environments inside and outside the home. Although removal of such animals from the home is encouraged, even after permanent removal of the pet it can still be many months before the allergen levels decrease [23].

Stopping smoking is the single most important thing a person can do to improve their health, at any age. Ireland has been a leading example, in regards to smoking, over the past decade where quite a lot of emphasis and government policy have been placed on a consumer directed anti-smoking campaign to great success [24]. According to Clark [25] the nurse is a facilitator who teaches clients how to selfassess, decide on wellness goals, plan on actions to meet those goals and self-evaluate success. It is imperative that nurses have a clear understanding of health psychology, social psychology and social cognition theories [26]. Changing a patient's health related behaviour is a notoriously problematic and complex task [8]. Nurses have an important role in the education of patients in relation to the importance of compliance in smoking cessation regimes to promote health. The fundamental goal of any nurse is to encourage and promote patients to choose or at least consider the healthier choice.

\section{Inhaler Techniques/Management Plan}

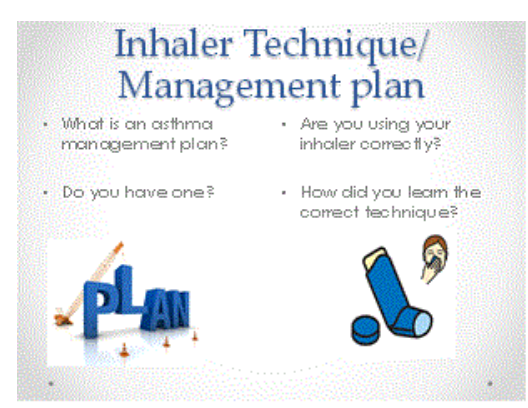

Figure 3: Inhaler techniques/management plan.

GINA guidelines [1] supports that all asthma patients should have access to skilled training of inhaler use along with information on asthma and personal self-management guidelines on symptoms, peak flow and asthma management plan. Good inhaler techniques are essential to ensure effective therapies. Also, patient techniques need to be reviewed at regular intervals. Inhalers are devices which deliver medication to the airways in the treatment of chronic respiratory diseases. When used correctly inhalers relieve and improve patients' symptoms. Asthmatic patient care can improve with consistent and frequent monitoring of patient inhaler techniques [27]. However, adherence to inhaler medication has been shown to be poor, leading to reduced clinical outcomes, medications wasted, and higher healthcare costs [28]. Poor inhaler techniques contribute to a lack of asthma control which may contribute to unnecessary treatment and hospitalization [29] (Figure 3).

Holmes et al. [28] conducted a study where an acoustic monitoring device was attached to the patient's inhaler to record the sounds the patients produced while using their inhaler. It recorded the time and date patients' inhaler use. A system was developed to mechanically detect inhaler events from the audio signals and provide feedback regarding patient adherence. The results of the study were that $83 \%$ of the patients had the correct inhaler technique. Incorrect use of inhalers can be a challenge for health care workers in the treatment of asthma. Nurses have an important role to play in educating patients on the importance of compliance with their treatment. An important rule to remember is to reduce the number of devices and always give written instructions. The question is why do patients use their inhaler incorrectly or do nurses not spend enough time teaching patients their inhaler technique.

Hickey [30] suggests that ineffective inhaler technique leads to increase in exacerbations and poor management of the disease. Hickey [30] found that there is evidence suggesting that health professionals lack the ability to teach inhaler technique properly however another reason could be as simple as the patient forgetting the correct technique, reasons miss management is multifaceted. Nurses must consider patient empowerment, which involves the moving the power from nurses towards the patient. All patients must receive education regarding their inhaler technique and the dosage to be administrated.

Asthma education and self-care management are key recommendations for asthma management that can improve health outcomes [1]. All asthmatic patients should have a written management plan [31]. The use of asthma management plans help the patient take control of their condition and give the patient a clear pathway to follow. The Irish Asthma Society of Ireland has free confidential advice available from specialist nurses along with a number of documents that can be accessed on their web site. Personal asthma management plans can assist patients with their asthma and make the necessary changes in response to change in their asthma symptoms. As a result, asthma patients experience a one to two thirds reduction in admissions to emergency department and hospitals [1].

The Irish National Adult Literacy Agency (NALA) reports that one in six adults in Ireland have difficulty understanding basic written text [32]. This statistic is particularly concerning when considering that a large portion of instructions given by healthcare workers are in written format. If our patients cannot read English or where English may not be there first spoken language; understanding instructions will be difficult and one can expect a difficulty for those patients to adhere to the recommended treatment plans in order to achieve control over their medical condition. Healthcare workers need to consider their patients background when giving educating and adjust their methods accordingly to ensure their patients are correctly informed.

Health promotion is therefore an important consideration, by applying specific strategies; nurses can play an important role in the promotion of patient self-management. The costs of treating asthma can be preventable through lifestyle or behaviour changes and there is also significant potential for cost savings for effective interventions and educational programmes. Being educated about your health will improve patients' knowledge and life skills. Watson et al. [33] feels improved educational resources are needed to foster effective asthma support groups. It appears that nurses can adopt their own strategies during clinic sessions, however health care workers need to be aware of their communication patterns with regards to dependency and empowerment when working with and education the chronic ill patient [34]. Traynor [35] believes that it is important to understand the tensions that exist between individuals and powerful groups and asks the question is it really possible to offer all individuals treatments 
no matter the cost to alleviate all suffering. The Asthma Society of Ireland web site has material on how to assist, and guide selfmanagement for this chronic condition, improve patient education on asthma and self-management practices.

\section{Health Promotion}

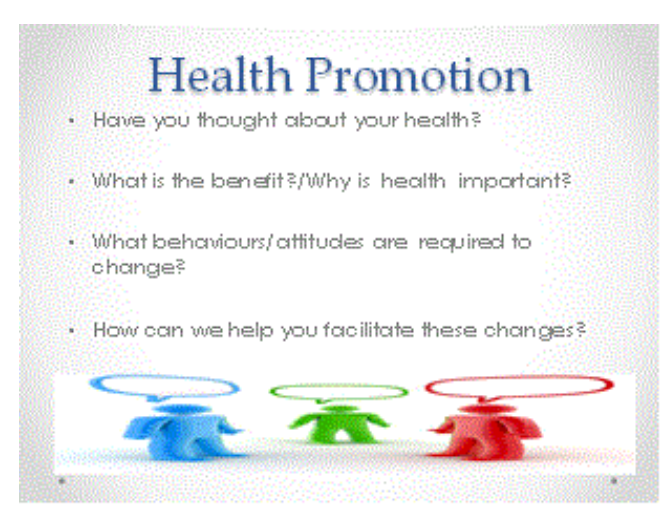

Figure 4: Health promotion.

Health promotion is a process of enabling people to increase control over their lives whereas health education is information given to influence people behaviours, attitudes and knowledge [3]. Health promotion and health education can be words spoken that are switchable and may cause confusion at times [36]. Health Promotion is a movement that endorses health and is linked by values; example would be the Ottawa Charter, empowerment and awareness. Under the Ottawa Charter there is a number of health promotion principles like building healthy public policy, creating supportive environments, developing personal skills, strengthening community action and reorient health service [3]. It is interesting to this day that this principle remains the focus and was discussed at the 8th global conference on health promotion in Helsinki 2013 (Figure 4).

Traynor [35] states that empowerment is some fundamental belief about human identity. Campbell and Gibson [17] believes empowerment is promoting health and enhancing individuals abilities to meet their needs, resolve their own difficulties and locate resources so individuals feel in control of their survival. While Whitehead [37] adds that community empowerment is a key to one's individual abilities in health promotion. In the case of empowering the asthmatic patient the aim would be to improve the patient's condition as there is no cure, enabling the patients take more responsibility for their health helping to take more control over their lives and highlight the opportunities that are available to them as individuals within their communities.

The contribution of nursing within this regard is to promote health and education regarding the inhaler technique and triggers that were discussed in slides 3 and 4 of the PowerPoint presentation. Tones and Tilford [38] argue that for self-empowerment, individuals need a high degree of actual control over their lives and health, a set of competences and certain personality characteristics. However the [24] suggests greater input from the community will improve the advocacy role of primary care teams in safeguarding those local and national social environmental issues which effect health, are acknowledged and addressed. Education has a role in the health of all patients and none more so than the asthmatic patient. Marmot et al. [39] suggests that investment in education has the greatest potential to reduce social determinant. With improved education on asthma there comes a greater awareness, knowledge and enhanced ability to make healthier choices.

In Ireland the National Health Promotion strategy creates an emphasis on population, group, topics and setting; all of these emphases mentioned are of equally significance and are intertwined. In 2013 the Department of Health's launched a new framework to improve health and well-being 2013-2025, following this framework a healthy Ireland survey was conducted in which the health of nation was reviewed. It was the first time a survey like this happened in Ireland since 2007 and the Minister for Health Dr Leo Varadkar hopes to findings to be published in the foreseeable future.

There are many theoretical models which presents structure and focus to health related decision making like the Health Belief Model founded by Rosenstock [40] modified by Becker and Trans theoretical Model theory/cycle of change which involves the progress through a number of stages: pre-contemplation, contemplation, preparation, action, maintenance and termination. There are deficiencies with each and every model, but each model has its own importance when related to different health factors $[8,26,41]$. The best known model is the Health Belief Model which was modified in the 1980s to explain why people fail to use health services. The negative aspect of this health belief model is that it does not examine the emotional and social aspect of health [38]. There is a model of chronic illness named Shifting Perspectives Model that ascended from the synthesis findings in qualitative research. The model indicates pathway to health professionals on how to supporting individual with chronic illness. The Shifting Perspectives Model helps users provide an explanation of chronically ill persons and their attention to symptoms over time, even harmful to their health and in ways that seem ill-advised [42].

Whitehead [37] developed the stage planning program model for health education and health promotion activity. This is very much an expert driven and bottom up approach model. One can look as far back too Florence Nightingale where she proposed the Nightingales Environmental Theory. Florence Nightingale's environmental model could be concluded 'that the client, the nurse, and the major environmental concepts are in balance' and if the environment are out of balance, the client expends unnecessary energy therefore the nurse's role is to place the client in the best position for nature to act upon him, thus encouraging healing [43]. Tones and Tilford [38] supports the contention that the process and outcomes of health promotion should be recorded in patients' notes and that further prospective health promotion needs should be identified when planning care. 
Page 5 of 6

\section{Conclusion}

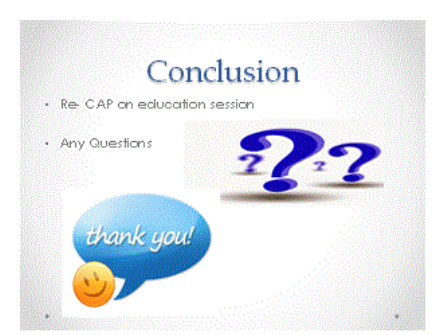

Figure 5: Conclusion.

This review is in support of the enclosed PowerPoint presentation, slides beginning by introducing health promotion followed by looking at asthma triggers and management techniques. Health promotion is defined as a prevention of unhealthy behaviour and promotion of physical, mental and social wellbeing. For complete health promotion there must be advocacy, enablement and medication. Advocacy creates favourable conditions for health, enablement reduces differences in health status and ensures opportunities and resources to achieve full health potential and mediation coordinates action. There are many triggers that where identified for the condition of asthma where some where discussed. The lack of good and quality inhaler techniques were shown to be a contributing factor towards asthma exacerbations which not only puts increased pressure on our health services but is also contributing towards a higher cost to the state. Health promotion is the process of empowering people to make healthy lifestyle choices and motivating them to become better self-managers. Asthma management plans were shown to be an important tool in the management of such a chronic condition. As a part of this, health education and health promotion has become widely recognised as a professional role of health care providers and it is significance in nursing. Health is a personal, social and economic good wellbeing of individuals and of the population as a whole (Figure 5).

Today, health education and health promotion become an integral part of the nursing profession. Nurses have a specific role to play in promoting health, not only by taking part in one-to-one nurse patient interventions, but also by becoming involved in organisational and policy based practice, quality initiatives and associated strategies and policy development. The Asthma Society of Ireland web site has material on how to assist, and guide self-management for the chronic condition of asthma and improve patient education on asthma and self-management practices.

The costs of treating asthma are preventable through lifestyle or behaviour changes and there is also significant potential for cost savings for effective interventions and educational programmes. Health promotion activities should be increased in health systems across the world. Governments should identify the most important risk factors in their countries and implement health promotion programs accordingly.

\section{References}

1. GINA (2015) Global Strategy for Asthma Management and Prevention.

2. Naik-Panvelkar P, Armour C, Rose JM, Saini B (2012) Patient preferences for community pharmacy asthma services: A discrete choice experiment. Pharmacoeconomics 30: 961-976.
3. WHO (1986) The Ottawa Charter for Health Promotion.

4. U.K. National Health Service (2015) Asthma (Online).

5. U.S. National Institute of Allergy and Infectious Diseases (2011) Asthma in the US.

6. Asthma Society of Ireland (2012) Annual Report 2012, Asthma Society of Ireland.

7. Shoqirat N, Cameron S (2013) A qualitative study of hospital patients' understanding of health promotion. J Clin Nurs 22: 2714-2722.

8. Nutbeam D (1999) The challenge to 'provide' evidence in health promotion, Health Promotion International 14: 99-101.

9. International Council of Nurse (2012), The ICN Code of Ethical for Nurses.

10. Department of Health (2011) Your health is your wealth: A policy framework for a healthier Ireland 2012-2020. Department of Health, Dublin.

11. Ritz T, Bobb C, Griffiths C (2014) Predicting asthma control: the role of psychological triggers. Allergy Asthma Proc 35: 390-397.

12. Yorke J, Fleming SL, Shuldham C (2007) Psychological interventions for adults with asthma. The Cochrane Collaboration, Cochrane Airways Group.

13. Sharon LL, Ruff Dirksen S, McLean Heitkemper M, Bucher L (2013) Medical-surgical nursing: Assessment and management of clinical problems, 9th ed. Elsevier Press.

14. The Mayo Clinic (2014) Asthma treatment: Do complementary and alternative approaches work?

15. Gøtzsche PC and Johansen HK (2011) House dust mite control measures for asthma. The Cochrane Collaboration, Cochrane Airways Group.

16. Singh M, Jaiswal N (2013) Dehumidifiers for chronic asthma. See comment in PubMed Commons below Cochrane Database Syst Rev : CD003563.

17. Campbell F and Gibson PG (2009) Feather versus non-feather bedding for asthma. The Cochrane Collaboration, Cochrane Airways Group.

18. Abramson MJ, Puy RM, Welner JM (2009) Injection allergen immunotherapy for asthma. The Cochrane Collaboration, Cochrane Airways Group.

19. Farrell C, McAvoy H, Wilde J; Combat Poverty Agency (2008) Tackling health inequalities -An All-Ireland approach to social determinants. Dublin: Combat Poverty Agency/Institute of Public Health in Ireland.

20. Vermont Department of Health (2013) Healthy Vermonters 2020 improving the health of Vermonters, Vermont State Asthma Plan 2013-2018.

21. Denning DW, Pashley C, Hartl D, Wardlaw A, Godet C, et al. (2014) Fungal allergy in asthma-state of the art and research needs. Clin Transl Allergy 4: 14.

22. Kilburn S, Lasserson TJ, McKean M (2003) Pet allergen control measures for allergic asthma in children and adults. Cochrane Database Syst Rev CD002989.

23. Breathingwell (2012) Asthma Triggers.

24. Department of Health and Children (2000) Towards a tobacco free society: Report of the tobacco free policy review group.

25. Clark C (1997) Wellness Practional, Springer, NY.

26. Serembus JF (1998) The healthy heart: Health promotion and maintenance. Holist Nurs Pract 12: 44-51.

27. Joels C (2012) Protocol for assessing inhaler technique in patients with asthma. Nurs Stand 26: 43-47.

28. Holmes MS, D’Arcy S, Costello RW, Reilly RB (2014) Acoustic analysis of inhaler sounds from community-dwelling asthmatic patients for automatic assessment of adherence. Journal of Translational Engineering in Health and Medicine 2.

29. Giraud V, Roche N (2002) Misuse of corticosteroid metered-dose inhaler is associated with decreased asthma stability. Eur Respir J 19: 246-251.

30. Hickey S (2014) Understanding the impact of inhaler technique on asthma and COPD. Academic Journal 12: 492-496. 
Citation: Murray B, O'Neil M (2016) Nurses Role in Delivering the Message: The Value of Health Promotion and Patient Education in the SelfCare Management of Adults with Asthma. J Nurs Care 5: 351. doi:10.4172/2167-1168.1000351

Page 6 of 6

31. Health Service Executive Ireland (2013) Emergency Asthma Guideline, National Asthma Clinical Care Programme.

32. ALA (2014) Literacy In Ireland (online).

33. Watson R, Castleden H, Tui'kn Partnership, Masuda J, King M, et al. (2012) Identifying gaps in asthma education, health promotion, and social support for Mi'kmaq Families in Unama'ki (Cape Breton), Nova Scotia, Canada. Preventing Chronic Disease 9.

34. Lawn S, Delany T, Sweet L, Battersby M, Skinner TC (2014) Control in chronic condition self-care management: How it occurs in the health worker-client relationship and implications for client empowerment. J Adv Nurs 70: 383-394.

35. Traynor M (2003) A brief history of empowerment: Response to discussion with Julianne Cheek. Primary Health Care Research and Development 4: 129-136.

36. Maben J, Clark JM (1995) Health promotion: A concept analysis. J Adv Nurs 22: 1158-1165.
37. Whitehead D (2009) Reconciling the differences between health promotion in nursing and 'general' health promotion. Int J Nurs Stud 46: 865-874.

38. Tones K, Tilford S (2001) Health Promotion effectiveness, efficiency and equity, Nelson Thornes Ltd., United Kingdom.

39. Marmot M, Friel S, Bell R, Houweling TA; Commission on Social Determinants of Health (2008) Closing the gap in a generation: Health equity through action on the social determinants of health. Lancet 372 : 1661-1669.

40. Rosenstock IM (1966) Why people use health services. Milbank Mem Fund Q 44: Suppl: 94-127.

41. Molloy J, Caraher M (2000) Public health and the role of the nurse: The need for greater clarity. Br J Community Nurs 5: 431-435.

42. Paterson BL (2003) The shifting perspectives model of chronic illness. Primary Health Care Research and Development 4:129-136.

43. Gunawan J (2013) Summary of Florence Nightingale Theory. 